\title{
Democracy Justifies the Means: Political Group Structure Moderates the Perceived Legitimacy of Intergroup Aggression
}

\author{
Juan M. Falomir-Pichastor \\ Christian Staerklé \\ University of Geneva, Switzerland \\ Marie-Aude Depuiset \\ Fabrizio Butera \\ Pierre Mendès France University, Grenoble, France
}

The present research tested the hypothesis that the political structure of conflicting groups moderates perceived legitimacy of intergroup aggression. In two experiments, participants read scenarios of fictitious summer camps in which members of one group aggressed members of another group. The political structure of both the perpetrator and the victim groups was described as either egalitarian (defined with democratic decision-making procedures) or hierarchical (authoritarian decision-making procedures). Results of both experiments showed that aggressions perpetrated by members of egalitarian groups at the expense of members of hierarchical groups were evaluated as less illegitimate than aggressions committed in the three remaining conditions. This effect is discussed as a function of the higher social value attributed to democratic groups.

Keywords: intergroup conflict; aggression; legitimacy; decisionmaking procedures; democracy

\section{I} t is widely believed that the Machiavellian doctrineallowing, if necessary, violent and aggressive means to reach political goals-is no longer appropriate to resolve conflicts in the modern world. In democratic systems, rationality should prevail over brutality, so the story goes, and peaceful solutions based on diplomatic negotiation between the conflicting parties should be given preference. This expectation for peaceful solutions can be traced back to common beliefs that democratic political systems are based on rational decision making that should prevent irrational, aggressive behavior leading to destructive outcomes (Staerklé, Clémence, \& Doise, 1998). Historical observation indeed confirms that democratic states do not engage in armed conflict between them (Doyle, 1983), giving rise to a flattering reputation that democratic groups are fundamentally striving for peace whenever possible (see Healy, Hoffman, Beer, \& Bourne, 2002).

Political reality, however, betrays such noble principles. In recent years, democratic nations have initiated a number of armed conflicts and wars, albeit not against other democratic nations but against nondemocratic states. From the Algerian war to the latest invasions in Afghanistan and Iraq, from the Falklands' war to the bombing of the Federal Republic of Yugoslavia, there are numerous examples of aggressions that all were perpetrated by Western democratic nations at the expense of authoritarian or nondemocratic states. How can these aggressive state behaviors be justified without giving up the democratic principles of peace and rationality? We suspect that political leaders take advantage of democ-

\footnotetext{
Authors' Note: Fabrizio Butera is now at the University of Lausanne. This work was supported by the Swiss National Science Foundation and the "Avenir" program of the Rhône-Alpes regional council. This article was written while Christian Staerklé was a visiting fellow at University of California, Los Angeles, funded by an advanced researcher fellowship from the Swiss National Science Foundation. Part of this work was presented at VIII Congreso Nacional de Psicologia Social (Spain, 2003). We wish to express our gratitude to Eva G. T. Green, Gabriel Mugny, José-Miguel Fernandez-Dols, and two anonymous reviewers for their comments on previous versions of this article. Correspondence concerning this article should be addressed to Juan M. Falomir-Pichastor, Université de Genève, FPSE, Psychologie Sociale, 40 bd. du Pont d'Arve, CH-1205 Geneva, Switzerland; e-mail: Juan.Falomir@ pse.unige.ch.

PSPB, Vol. 31 No. 12, December 2005 1683-1695

DOI: $10.1177 / 0146167205278260$

(C) 2005 by the Society for Personality and Social Psychology, Inc.
} 
racy's good reputation because they are quick to point out that war against other nations is used only as a very last option, after the failure of all possible diplomatic alternatives. Hence, they imply that if democracies resort to aggressive conflict resolution, they must have good reasons to do so. This strategy seems to be quite convincing because in Western societies, in spite of sometimes considerable public opposition to war decisions, most aggressions have by and large been accepted and considered as legitimate.

The present article reports two studies that investigate perceived legitimacy of intergroup aggression in minimal experimental settings involving democratic-egalitarian groups and nondemocratic-hierarchical groups. Our main hypothesis is that the political structure of groups, in terms of their democratic or nondemocratic decisionmaking procedures, is a key determinant of perceived legitimacy of intergroup aggression. More specifically, aggressive behaviors should be considered less illegitimate when perpetrated by a democratic-egalitarian group and when they are perpetrated against an authoritarian-hierarchical group.

Because democratic and authoritarian political systems are difficult to experimentally manipulate, we studied, as a proxy, the evaluation of aggression with fictitious groups. Egalitarian groups were defined by the presence of collectively designated leaders and by participation of all group members in important decisions. In hierarchical groups, self-proclaimed leaders took decisions without consulting other group members. Aggression was defined as behavior carried out with the intention to cause harm to individuals or groups who wish to avoid such treatment (e.g., Berkowitz, 1993). We focus on perceived legitimacy of aggressions perpetrated in intergroup contexts, that is, members of one group attacking individuals belonging to another group.

\section{DETERMINANTS OF PERCEIVED LEGITIMACY \\ OF AGGRESSIVE BEHAVIORS}

Social psychological research has focused on four aspects of the aggression that perceivers use to judge the legitimacy of hostile acts: the nature of the act itself ("What happened?"), the perpetrator's motives ("Why was it done?"), the perpetrator's characteristics ("Who did it?"), and the target's characteristics ("Who was the victim?"). For the acts themselves, negative evaluations of harmful behaviors are mainly grounded on the perceived severity of its consequences (Feather, 1999). By and large, severely harmful acts are judged as less legitimate than innocuous acts (Robbennolt, 2000; Shaver, 1970).

With regard to motives, instrumental (i.e., intentional, "cold," planned) aggressions perpetrated to reach a goal are distinguished from hostile (i.e., "hot," unreasoned, and impulsive) aggressions intended to hurt someone (e.g., Bushman \& Anderson, 2001; Hart, 1968). In general, unintentional aggressions are evaluated less negatively than premeditated ones (Jones \& Davis, 1965; Malle, 1999). Furthermore, aggression is less illegitimate when the motives are reactive (e.g., selfdefense) rather than instrumental (e.g., to get a reward; Reeder, Kumar, Hesson-McInnis, \& Trafimow, 2002). Similarly, evaluations are more clement if the aggression is determined by situational rather than dispositional factors (Kelley, 1973).

The "Who did it?" factor of aggression legitimacy relates to perceived characteristics of the perpetrator. Feather (1999) has extensively studied how perceived characteristics of offenders shape justice judgments. His research demonstrates that perceived responsibility of the offender is a key factor for support for harsher penalties, thereby reflecting a lower perceived legitimacy of the offense. Feather also showed that offenses committed by authority figures and high-status persons are judged as less serious than those committed by low-status individuals. Another important factor is perceived similarity with the perpetrator. In general, the more similar an observer feels to the perpetrator, the more the aggression will be judged as legitimate (Fincham \& Jaspars, 1980). Identification with and perceived closeness to perpetrators diminishes attribution of responsibility for the aggressive act (McKillip \& Posavac, 1975; Shaver, 1970). A social identity approach to aggression legitimacy follows a similar logic (Tajfel \& Turner, 1986) because it implies that aggressions perpetrated by ingroup members, or those perpetrated against outgroup members, should be evaluated less negatively.

Finally, perceived characteristics of the victims also shape the evaluation of aggression. Taking a social identity perspective on victims, Gordijn, Wigboldus, and Yzerbyt (2001; Dumont, Yzerbyt, Wigboldus, \& Gordijn, 2003) found that observers of an unfair and intentional behavior harming others (but not themselves) led to more anger when the victims were perceived as ingroup rather than outgroup members. Similarly, Baldus, Woodworth, and Pulanski (1990) have shown in their analysis of the justice system in Georgia that harsher sentences were passed on offenders who committed crimes against Whites rather than against Blacks, independently of the ethnicity of the aggressor. Thus, in this context, victim ethnicity overrode offender ethnicity as a determinant of the harshness of the legal sentence.

Another general factor underlying legitimacy judgments of aggression relates to perceived deservingness of victims. Crandall and Beasley (2001) neatly summarized a widespread tendency for judging victims by their deservingness with the tautological lay reasoning, "Bad people deserve bad treatment, and good people deserve 
good treatment" (p. 79). This would suggest that the more victims are seen to deserve bad treatment, the more aggressive behavior against them should be perceived as legitimate (Lerner, 1980). Blaming stereotypical features of the victim group for the aggression, thereby attributing at least partial responsibility for their own trouble, is indeed a powerful strategy to provide legitimacy to aggressive intergroup behavior (Milgram, 1974; Miller, 2001; Staub, 1989). More generally, disadvantaged or subordinate groups are easily seen as scapegoats and blamed for their own and others' misfortunes by dominant groups (Yzerbyt \& Rogier, 2001).

\section{DEMOCRATIC AND NONDEMOCRATIC AGGRESSION AND VICTIMIZATION}

These four aspects of the aggression underlie judgments of legitimacy of aggressive behaviors but are largely unrelated to group structure, which is the focus of the present investigation. To understand how perceivers evaluate aggressive acts perpetrated by egalitarian or hierarchical groups against egalitarian or hierarchical groups, two theoretical approaches may be considered. First, we suggest that group structure gives observers cues regarding the "social value" of group members. Second, group structure also gives cues regarding the legitimacy of behaviors performed either by or against them.

People easily impute to individual members of a group the motives and attitudes that would explain the actions of the total group (Allison \& Messick, 1987). We argue, in addition, that not only do perceived individual attitudes of group members reflect group decisions but that decision-making procedures are used by perceivers as cues about individual group members' characteristics. Prior research has provided support for this hypothesis by showing that democratic and nondemocratic groups elicit particular stereotypical images of their members (Staerklé, 2005). Members of democratic societies are perceived as relatively more tolerant, free, orderly, peaceful, and politically involved. Conversely, members of nondemocratic societies are associated with psychological weakness, obedience, and manipulation by their leaders. They are also more likely to be perceived as disorderly and politically passive. In sum, these results suggest that lay perceivers easily associate the system and its members by endorsing the saying that "the people get the government they deserve" (Staerklé et al., 1998).

An important implication of this tendency to infer individual characteristics on the basis of democratic and authoritarian decision-making procedures is that inferences are not value-neutral but give perceivers cues as to the social value of group members. Independence and individual autonomy are culturally more valued than obedience and collectivism, especially in Western societ- ies (Beauvois, 2005; Lorenzi-Cioldi, 1998; Sampson, 1988). In hierarchical groups, group members are perceived as followers who are easily manipulated and interchangeable, and therefore less socially valued than "free" individuals. In egalitarian groups, however, perceivers expect an absence of power relationships between members and thus attribute more social value to group members.

Group structure and decision-making procedures not only provide cues about the social value of group members but also regarding the legitimacy of a decision concerning the group. This argument is supported by research on procedural fairness that has firmly established that people care not only about the outcomes of decisions but also about how these decisions are reached (Tyler, 1997). Procedures are perceived as fair when people have their say, when they can "voice" their concerns (Lind \& Tyler, 1988). How decisions are taken in a group largely depends on its political structure (Azzi \& Jost, 1997). In egalitarian or democratic groups, decisions are taken with some form of consultation of group members, for example, through collective deliberation leading to consensual decisions or through majority-rule decisions. In hierarchical or authoritarian groups, however, leaders take decisions without the need for collective legitimacy. Hence, group structure may be used as a cue for imputing the legitimacy of the actions perpetrated by group members and may thereby also give an indication of the trustworthiness of its members. Democratic decisions should be perceived as inherently more legitimate than authoritarian decisions, independently from the actual content of the decision, because they match socially valued decision making in which all group members have their say. This leads to a situation in which egalitarian group structure encapsulates the potential to justify unfair actions. We argue in addition that even isolated actions carried out by members of an egalitarian rather than a hierarchical group should be perceived as less unfair, particularly when they have negative consequences for members of hierarchical rather than egalitarian groups.

\section{OVERVIEW AND HYPOTHESES}

Because democratic groups are socially more valued than authoritarian groups, and because democratic decision making is more legitimate than authoritarian decision making, we hypothesized that the political structure of groups, in terms of their democratic or nondemocratic decision-making procedures, will influence the perceived legitimacy of intergroup aggression. Two experiments examined the impact of the political structure of perpetrator and victim groups on the perceived legitimacy of aggressive behavior. Inspired by Sherif's Robber Cave experiments, the cover story described a 
study, fictitious but allegedly real, carried out in summer camps in which adolescents were randomly separated into two groups. Participants were told that the results of this study indicated that the structure of social groups appeared to be either egalitarian or hierarchical. Participants were then informed that members of one of the groups (either egalitarian or hierarchical) aggressed members of the opposite group (either egalitarian or hierarchical). They were then asked to evaluate the legitimacy of this aggression.

Our theoretical reasoning leads us to offer two alternative predictions. First, a perpetrator and a victim main effect: Intergroup aggressions perpetrated by members of egalitarian groups should be perceived as more legitimate than aggressions perpetrated by members of hierarchical groups; similarly, aggressions against hierarchical groups should be perceived as more legitimate than aggressions against egalitarian groups.

A second, alternative prediction takes heed of the meaning attributed to the four possible combinations in this paradigm. It seems plausible to assume a high baseline level of perceived illegitimacy of aggression, indicating that, by default, aggression is intolerable. However, under some circumstances, aggression may become more tolerable. Aggression may to some extent be condoned if the perpetrator group is egalitarian and if the victim group is hierarchical. Because of the social value of the egalitarian groups, aggressions against egalitarian victims may be strongly condemned and may be perceived as intolerable independently of the perpetrator group's political structure. Indeed, aggressions between egalitarian groups should not be accepted at all because peaceful solutions such as negotiation should be given preference in both groups. This pattern of results would be evidenced with an interaction effect between the perpetrator and victim group structure such that aggressions perpetrated by egalitarian groups against hierarchical groups should be perceived as the most legitimate (or the least illegitimate) configuration of intergroup aggression.

In addition to the test of these two hypotheses, both studies also explored the role of participants' identification with the aggressor and the victim groups in accounting for the perceived legitimacy of the aggression. First, we examined whether the political structure of the groups influenced identification with members of the two groups. Because of their higher social value, we expect identification with egalitarian groups to be higher than with hierarchical groups. Second, we also explored whether identification scores mediated the effect of group structure on perceived legitimacy of the aggression. Indeed, it could be expected that greater identification with an egalitarian perpetrator group leads to condone the aggression, whereas identification with an egalitarian victim group results in greater rejection of the aggression (see Gordijn et al., 2001, for similar analyses in terms of emotional reactions).

\section{EXPERIMENT 1}

\section{Method}

\section{PARTICIPANTS AND DESIGN}

The participants were 82 psychology and educational sciences undergraduates at University of Grenoble, France ( 70 women), who received extra course credit for participation. Their age ranged from 18 to 50 years $(M=$ $22.16, S D=5.87)$. Participants were randomly assigned to one of the four conditions of a 2 (perpetrator group: egalitarian vs. hierarchical) $\times 2$ (victim group: egalitarian vs. hierarchical) experimental design.

\section{PROCEDURE}

The experiment was carried out during a social psychology class and was presented as an exercise in which students were asked to read a description of a study on group processes carried out in several holiday camps for adolescents. They were told that at the beginning of each camp, adolescents were randomly split into two groups, and each group independently accomplished activities such as village building, cooking, or maintenance. The researchers working at the camp merely observed how the groups spontaneously organized themselves to get their jobs done. They concluded that two main types of group structures could be distinguished: egalitarian and hierarchical. For egalitarian groups, participants learned that (a) the groups collectively designated some adolescents as responsible for coordination of group activities (i.e., the leaders), (b) important decisions were taken collectively in an assembly in which all group members participated in the discussions, and (c) the researchers called these groups egalitarian because all group members had equal decision power. In addition, participants were told that in hierarchical groups, (a) some adolescents were self-proclaimed leaders, responsible for coordination of group activities; (b) important decisions were taken by these leaders without consulting other group members; and (c) researchers called these groups hierarchical because only the leaders had decision power. To avoid the perception of differences in the quality of the experience, participants also were told that the adolescents in both kinds of groups expressed equal satisfaction with their group experience and with the holiday camp in general.

Then, participants were informed that the present class exercise focused on an event that raised controversy among camp organizers as well as researchers. In one of the camps, there were two groups, called the Blues and the Reds. One day, the Blues protested against 
unfair treatment as they considered that they were given less food by the camp organizers than the Reds. The following night, during an outing in the forest, angry members of the Blues aggressed and stole a small amount of money from two members of the Reds. Because it was dark, the victims were unable to identify the aggressors who remained unsanctioned. Participants were then told that the aim of the present exercise was to evaluate the legitimacy of this aggression.

\section{INDEPENDENT VARIABLES}

Depending on the experimental condition, the perpetrator group (the Blues) was egalitarian and the victim group (the Reds) hierarchical, or vice versa, or both groups were either egalitarian or hierarchical. This information was repeated three times in the description of the summer camp to make sure that the participants associated each group with the respective internal structure.

\section{DEPENDENT VARIABLES}

As a manipulation check, participants were asked to assess the extent to which the members of the perpetrator group were perceived as having hierarchical relations with their leaders, namely, on three items: manipulated by their leaders, independent (reverse-scored), and subordinate, on 7-point scales $(1=$ not at all, $7=\mathrm{com}$ pletely). No manipulation check for the victim group structure was included but this shortcoming was corrected in Experiment 2. The three items were averaged into a composite score of perception of hierarchical structure within the perpetrator group $(M=4.11, S D=$ $1.18, \alpha=.67)$.

The main measure of perceived illegitimacy of the aggression consisted of six items with which participants evaluated the act. They indicated to what extent they found the aggression violent, severe, acceptable (reversed), understandable (reversed), legitimate (reversed), and unfair. All answers were reported on 7point scales $(1=$ not at all, $7=$ completely $)$. A score was computed by averaging the responses to the six items measuring the perceived illegitimacy of the aggression so that a higher score indicates a higher perception of illegitimacy $(M=5.28, S D=.98, \alpha=.78)$.

A last set of questions measured identification with each of the two groups. On 7-point scales, participants had to indicate to what extent they felt close, identified, and similar to the members of each of the two groups. Two scores were computed: identification with the perpetrator group $(M=2.49, S D=1.24, \alpha=.86)$ and with the victim group ( $M=2.80, S D=1.15, \alpha=.83)$; the higher the score, the greater the identification. These scores were positively correlated $(r=.58, p<.001)$. These results suggest that participants perceived both groups as quite distant from themselves.
TABLE 1: Perceived Illegitimacy of Aggression (Experiment 1)

\begin{tabular}{lccccc}
\hline & \multicolumn{4}{c}{ Perpetrator Group } \\
\cline { 2 - 3 } \cline { 5 - 6 } Victim & \multicolumn{2}{c}{ Egalitarian } & & \multicolumn{2}{c}{ Hierarchical } \\
\cline { 2 - 3 } \cline { 5 - 6 } Group & Egalitarian & Hierarchical & & Egalitarian & Hierarchical \\
\hline M & 5.46 & 4.81 & & 5.25 & 5.58 \\
SD & 0.93 & 1.03 & & 1.04 & 0.83 \\
\hline
\end{tabular}

NOTE: Number of cases per cell from left to right: 22, 18, 20, and 22.

Finally, participants were thoroughly debriefed on the purpose of the experiment and on the use of experimental methods in social psychology.

Results

\section{MANIPULATION CHECK}

The 2 (perpetrator group: egalitarian vs. hierarchical) $\times 2$ (victim group: egalitarian vs. hierarchical) ANOVA performed on the perception of hierarchical structure in the perpetrator group revealed a main effect of the perpetrator group structure, $F(1,78)=18.34, p<$ .001: As expected, members of the hierarchical group were perceived as having more hierarchical relationships $(M=4.59)$ than members of the egalitarian group $(M=3.61)$. Neither the effect of the victim group structure nor the interaction effect was significant (both $p$ s > $.10)$.

\section{PERCEIVED ILLEGITIMACY OF THE AGGRESSION}

Means across conditions are presented in Table 1. The 2 (perpetrator group: egalitarian vs. hierarchical) $\times$ 2 (victim group: egalitarian vs. hierarchical) ANOVA on perceived illegitimacy of the aggression revealed that both main effects were nonsignificant, $F(1,78)=1.66$, $n s$, for the perpetrators, and $F(1,78)<1$, ns, for the victims. However, the analysis yielded a significant interaction effect between the two factors, $F(1,78)=5.32, p<.03 .{ }^{1} \mathrm{To}$ test our second prediction that the aggression is perceived as less illegitimate when the perpetrator group is egalitarian and the victim group hierarchical, we performed a planned comparison $(1,-3,1,1$, in the order presented in Table 1). This analysis confirmed that the critical condition $(M=4.81)$ significantly differed from the pooled remaining three conditions $(M=5.43)$, $t(78)=2.43, p<.02$. More specifically, the aggression against hierarchical groups was perceived as less illegitimate when the perpetrator group was egalitarian rather than hierarchical, $t(78)=2.50, p<.02$, but no differences were observed when the victims were egalitarian, $t(78)=$ $0.72, p<.46$. Finally, the critical condition also differed significantly from the condition in which both the perpetrator and the victim groups were egalitarian, $t(78)=$ $2.12, p<.04$, whereas the difference between the two conditions involving hierarchical perpetrators was not 
significant. These results support our second prediction involving an interaction effect between egalitarian and hierarchical perpetrator and victim groups.

\section{IDENTIFICATION WITH THE PERPETRATOR}

AND THE VICTIM GROUPS

The $2 \times 2 \times 2$ mixed ANOVA with the two identification scores as repeated measures and the experimental variables as between-subjects factors showed a significant within-subjects effect, $F(1,78)=10.12, p<.002$ : Identification, although low in general, was higher with the victim group $(M=2.80)$ than with the perpetrator group $(M=2.49)$. The interaction between the within-subjects factor and the victim group structure also was significant, $F(1,78)=6.24, p<.02$. Furthermore, the interaction between the within-subjects factor and the perpetrator group structure reached marginal significance, $F(1$, 78) $=3.87, p<.06$.

In regard to within-subjects comparisons, a stronger identification with the victim group $(M=3.06)$, as compared to the perpetrator group $(M=2.42)$, was observed when the victim group was egalitarian, $p<.001$, but not when the victim group was hierarchical (respectively, $M s=2.47$ and 2.36; $p<.14)$. Identification with the victim group was stronger $(M=2.96)$ than with the perpetrator group $(M=2.38)$ when the perpetrator group was hierarchical $(p<.001)$ but not when perpetrators were egalitarian (respectively, $M \mathrm{~s}=2.57$ and $2.40 ; p<.40$ ). Considering now between-subjects comparisons, analyses revealed no significant effect for the identification with the perpetrator group. In regard to identification with the victim group, the main effect of the victim group structure was significant $(p<.02)$ and the main effect of the perpetrator group structure was marginally significant $(p<.09)$. Participants identified more with the victim group when it was egalitarian rather than hierarchical and tended to identify more when the perpetrators belonged to a hierarchical rather than to an egalitarian group. In sum, identification with the victim group was higher than identification with the perpetrator group, and this effect was enhanced when the victim group was egalitarian and the perpetrator group was hierarchical. However, no differences appeared in identification with the perpetrator group.

Even if identification with the perpetrator group was negatively correlated with perceived illegitimacy of the aggression $(r=-.44, p<.001)$, this factor cannot be considered a mediator between group structure and perceived legitimacy of the aggression because group structure did not influence identification with the perpetrator group. To examine whether identification with the victim group mediated this effect, we used Baron and Kenny's (1986) procedure. First, the contrast relative to the interaction hypothesis $(1,-3,1,1)$ was used as the independent variable, which was significantly related to the dependent variable, that is, perceived illegitimacy, $\beta=-.26, p<.02$ (see previous analyses); second, identification with the victim group (the mediating variable) was also significantly related to perceived illegitimacy, $\beta=-.24, p<.03$; and third, the contrast was marginally related to identification with the victim group, $\beta=-.18$, $p<.10$. Finally, when both the experimental contrast and the identification with the victim group were included in the equation, the effect of the identification was significant, $\beta=-.30, p<.004$, but the effect of the contrast also remained significant, $\beta=-.31, p<.003$. In sum, identification scores were related to the perceived illegitimacy of the aggression, but neither identification with the victim group nor identification with the perpetrator group mediated the effect of perpetrator and victim group structure on perceived illegitimacy of the aggression.

\section{Discussion}

The results of Experiment 1 provided support for our second prediction involving an interaction effect between the perpetrator and the victim groups. No evidence supporting our first prediction involving two main effects was found. Results showed that notwithstanding a high baseline level of perceived illegitimacy, an aggression is to some extent condoned when the perpetrators belong to an egalitarian group and the victims to a hierarchical group. Indeed, in this particular configuration, the aggression was judged as less illegitimate than the same aggression in the three remaining configurations of the victim-perpetrator relationship.

The observed interaction effect shows that, on one hand, aggressions perpetrated against members of egalitarian groups are perceived as highly illegitimate independently of the political structure of the perpetrator group. Thus, participants also condemn the aggression of an egalitarian group against another egalitarian group, presumably because bad treatment of a socially valued group cannot be justified in any case. On the other hand, when the victim belonged to a less valued hierarchical group, participants condoned the aggression only if it was perpetrated by members of an egalitarian group.

As could be expected, participants identified more with the victim than with the perpetrator group. Furthermore, participants identified more with an egalitarian rather than with a hierarchical victim group and identified more with the egalitarian group when the perpetrators were hierarchical rather than egalitarian. However, identification with the perpetrator group was not affected by group structure. One possible explanation for this asymmetry is that identification with the perpetrator group was highly undesirable, even when this group was egalitarian. Therefore, identification was 
higher with the egalitarian victim group, and the aggression was in this case condemned independently of the perpetrator group structure. Finally, analyses showed that group identification did not mediate the effect of group structure on perceived illegitimacy of the aggression.

\section{EXPERIMENT 2}

To the best of our knowledge, Experiment 1 was the first study to find that an intolerable intergroup aggression can to some extent be condoned when the perpetrators belong to an egalitarian group and the victims to a hierarchical group. To confirm the validity of this finding, we tried to replicate it. In Experiment 2, the same materials, experimental manipulation, and procedure were used as in Experiment 1. In addition, this experiment addressed two new questions.

The first concern was that the effect was observed only at a fixed level of aggression severity, defined by the scenario. This is a concern because the level of severity has been shown to influence attributions of responsibility (Robbennolt, 2000): People attribute greater responsibility for a negative incident when its consequences are more severe. Similarly, the relative weight of situational forces decreases as the immorality of the act increases (Reeder \& Brewer, 1979). Consequently, the influence of victim and perpetrator group structure on aggression evaluation could vary as a function of the perceived severity of the aggression. Alternatively, if we find that aggression severity does not moderate the influence of group structure on perceived legitimacy of the aggression, the effect observed in Experiment 1 could be considered a more general effect occurring across different levels of severity. To examine whether aggression severity moderated perceived legitimacy of the aggression, Experiment 2 manipulated aggression severity.

The second concern is relative to the understanding of the previous findings at the level of group processes. It is plausible that the aggression described in the scenario is perceived as an isolated act committed by single individuals rather than as an act committed in the name of a group. Indeed, we reasoned that if the actions of egalitarian groups were judged as a function of their higher social value, any negative action performed by them should be seen as more justified, at least when the victims are not egalitarian. However, not only individual but also group-level acts carried out by egalitarian group members should be perceived as more justified, in particular when the victim group is hierarchical. To introduce both individual and group-level misfits in the scenario, in the present replication participants were told that members of the perpetrator group knew the identity of the perpetrators but subsequently covered them; participants were then asked to evaluate this form of ingroup protection.

\section{Method}

\section{PARTICIPANTS AND DESIGN}

The participants were 158 psychology and educational sciences undergraduates at University of Grenoble, France (133 women), who received extra course credit for participation. Their age ranged between 18 and 56 years $(M=22.50, S D=5.61)$. Participants were randomly assigned to one of the eight conditions of the 2 (aggression severity: low vs. high) $\times 2$ (victim group: egalitarian vs. hierarchical) $\times 2$ (perpetrator group: egalitarian vs. hierarchical) experimental design.

\section{PROCEDURE AND MATERIALS}

The procedure was the same as in Experiment 1, except for three variations. First, to introduce the aggression-severity manipulation, participants were told that two group members either beat up (low-severity condition) or beat up and stabbed (high-severity condition) a member of the rival group.

Second, manipulation checks similar to those used in Experiment 1 were introduced, but this time perception of the hierarchical nature of both the perpetrator and the victim groups was assessed. An averaged score of perception of hierarchical structure was computed for the perpetrator group $(M=4.51, S D=1.30, \alpha=.73)$ as well as for the victim group $(M=4.00, S D=1.20, \alpha=.76)$.

The third modification concerned the fact that all participants were told that members of the perpetrator group knew the identity of the perpetrators but that they covered them by not denouncing them. This change in the scenario allowed us to measure the perceived legitimacy of a group-level misdeed, that is, the covering of the perpetrators. They were then asked to evaluate this covering with the same items used to assess perceived aggression legitimacy (violent, severe, acceptable, understandable, legitimate, and unfair). An averaged score of perceived illegitimacy of the ingroup solidarity (i.e., uncooperative cover behavior) was computed, after reversing the appropriate items, so that a higher score indicates a higher perception of illegitimacy $(M=4.13$, $S D=1.03, \alpha=.74$ ).

Finally, the measure of perceived aggression illegitimacy $(M=5.79, S D=0.82, \alpha=.70)$ and of identification with both groups were the same as in Experiment 1 . Perceived aggression illegitimacy was positively correlated with perceived covering illegitimacy $(r=.46$, $p<.001)$. Two scores of identification were computed for the perpetrator group $(M=2.32, S D=1.26, \alpha=.90)$ and for the victim group $(M=2.70, S D=1.32, \alpha=.87)$. As in Experiment 1, these scores were positively correlated 
$(r=.53, p<.001)$, suggesting that participants distanced themselves from both groups.

Results

\section{MANIPULATION CHECKS}

Perception of the perpetrator group. The $2 \times 2 \times 2$ ANOVA performed on the mean score of the perception of a hierarchical structure in the perpetrator group yielded three significant main effects. The effect of the perpetrator group structure confirmed the effectiveness of the manipulation because the members of a hierarchical group were perceived as more hierarchical $(M=5.28)$ than the members of an egalitarian group $(M=3.79)$, $F(1,149)=89.54, p<.001$. The main effect of the victim group structure, $F(1,149)=18.13, p<.001$, indicated that the members of the perpetrator group were perceived as more hierarchical when the victim group was egalitarian $(M=4.82)$ than when it was hierarchical $(M=$ 4.19). Finally, the main effect of aggression severity, $F(1$, $149)=4.40, p<.05$, revealed that the members of the perpetrator group were perceived as more hierarchical when the severity was high $(M=4.67)$ rather than low $(M=$ 4.36). No interaction effect was significant (all $p \mathrm{~s}>.10$ ).

Perception of the victim group. The $2 \times 2 \times 2$ ANOVA performed on the mean score indicating the perception of a hierarchical structure of the victim group revealed two main effects and an interaction effect. The main effect of the victim group structure, $F(1,147)=73.45, p<.001$, confirmed that this manipulation was effective: A hierarchical group was perceived as more hierarchical $(M=$ 4.65) than an egalitarian group $(M=3.37)$. The main effect of the perpetrator group structure also was significant, $F(1,147)=17.04, p<.001$ : The victim group members were perceived as more hierarchical when the perpetrator group was egalitarian $(M=4.27)$ than when it was hierarchical $(M=3.71)$. Finally, a significant interaction between the victim and the perpetrator group structure, $F(1,147)=10.62, p<.001$, revealed that the perception of the hierarchical victim group did not depend on the perpetrator group structure $\left(M_{\text {hierarchical }}=4.60\right.$, $\left.M_{\text {egalitarian }}=4.72, p>.50\right)$, whereas egalitarian victim groups were perceived as more hierarchical when the perpetrator group was egalitarian $(M=3.90)$ rather than hierarchical $(M=2.76, p<.001)$. No other effect was significant. $^{2}$

\section{ILLEGITIMACY PERCEPTIONS}

Means across conditions are presented in Table 2. We first tested for differences between the perceived legitimacy of the individual- and group-level behavior. A $2 \times 2 \times$ $2 \times 2$ mixed-model ANOVA was performed with the two perceived illegitimacy scores (individual aggression and group covering) as repeated measures and the experimental factors as between-subjects factors. This analysis
TABLE 2: Perceived Illegitimacy of Aggression and Covering (Experiment 2)

\begin{tabular}{|c|c|c|c|c|}
\hline \multirow{3}{*}{$\begin{array}{l}\text { Victim } \\
\text { Group }\end{array}$} & \multicolumn{4}{|c|}{ Perpetrator Group } \\
\hline & \multicolumn{2}{|c|}{ Egalitarian } & \multicolumn{2}{|c|}{ Hierarchical } \\
\hline & Egalitarian & Hierarchical & Egalitarian & Hierarchical \\
\hline \multicolumn{5}{|c|}{ Aggression } \\
\hline$M$ & 5.77 & 5.44 & 5.91 & 6.04 \\
\hline$S D$ & 0.79 & 0.83 & 0.78 & 0.79 \\
\hline \multicolumn{5}{|c|}{ Covering } \\
\hline$M$ & 4.14 & 3.79 & 4.20 & 4.40 \\
\hline$S D$ & 0.92 & 0.98 & 1.18 & 0.99 \\
\hline
\end{tabular}

NOTE: Number of cases per cell from left to right: 44, 38, 37, and 39.

revealed a main effect of the within-subjects factor, $F(1$, $149)=435.86, p<.0001$, indicating that the individual aggression ( $M=5.79)$ was evaluated as more illegitimate than the group-level covering $(M=4.13)$. No other within-subjects effects were observed (all $p \mathrm{~s}>.15$ ), suggesting that misdeeds at both levels were evaluated similarly. In regard to between-subjects effects, the analyses revealed a significant main effect of the aggression severity, $F(1,149)=15.60, p<.001$, the main effect of the perpetrator group, $F(1,149)=15.60, p<.001$, as well as the interaction between victim and perpetrator group, $F(1$, $149)=5.10, p<.025 .{ }^{3}$ The results of the univariate analyses are presented below.

Perceived illegitimacy of the aggression. The $2 \times 2 \times 2$ ANOVA on perceived aggression illegitimacy revealed a significant main effect of aggression severity, $F(1,149)=$ $7.81, p<.01$, indicating that the aggression in which the victim was beaten up and stabbed was considered more illegitimate $(M=5.97)$ than the aggression where the victim was "only" beaten up $(M=5.62)$. The main effect of the victim group structure was not significant, $F(1,149)=$ $0.63, p<.43$, but the main effect of the perpetrator group structure was significant, $F(1,149)=8.95, p<.01$ : The aggression was considered as more illegitimate when the perpetrator group was hierarchical $(M=5.98)$ rather than egalitarian $(M=5.62)$. However, the interaction between the two group structures appeared to be marginally significant, $F(1,149)=3.37, p<.07$, suggesting that the main effect of the perpetrator group structure was moderated by the victim group structure. The planned comparison testing whether the aggression was perceived as less illegitimate when the perpetrator group was egalitarian and the victim group hierarchical $(1,-3$, 1,1 , in the order presented in Table 2) confirmed this prediction: Aggression was perceived as less illegitimate in the condition where the perpetrator group was egalitarian and the victim group hierarchical $(M=5.44)$, compared to the pooled remaining three conditions $(M=5.90), t(154)=3.12, p<.002$. More specifically, the aggression was perceived as less illegitimate when the 
perpetrator group was egalitarian rather than hierarchical, when the victim group was hierarchical, $t(154)=$ $3.24, p<.001$, but not when the victim group was egalitarian, $t(154)=0.79, p<.43$. When perpetrators were egalitarian, the difference between hierarchical and egalitarian victims was significant, $t(154)=2.55, p<.02$. When perpetrators were hierarchical, in turn, the difference between hierarchical and egalitarian victims was only marginally significant, $t(154)=1.86, p<.07$. Overall, these results provide support for the interaction hypothesis; moreover, a perpetrator group main effect also was found.

Perceived illegitimacy of covering perpetrators. The $2 \times 2 \times 2$ ANOVA showed a significant main effect of aggression severity, $F(1,149)=14.59, p<.001$ : Covering the perpetrators was seen as less acceptable when the aggression severity was high $(M=4.43)$ than when it was low $(M=$ 3.84). Again, this factor did not interact with the group structure factors. The victim group structure did not reach the level of significance, $F(1,149)=0.21, p<.65$, but the main effect of the perpetrator group structure was significant again, $F(1,149)=4.89, p<.05$ : Covering was less illegitimate for the egalitarian $(M=3.97)$ than for the hierarchical $(M=4.30)$ perpetrator group. And again, the interaction between the two group structure factors was marginally significant, $F(1,149)=3.25, p<$ .08 , suggesting that the victim group structure moderated the main effect of the perpetrator group structure. The planned comparison performed to directly test that covering the perpetrators was less illegitimate when the perpetrator group was egalitarian and the victim group hierarchical $(1,-3,1,1$, in the order presented in Table 2) confirmed that the covering was perceived less illegitimate in such a condition $(M=3.78)$ than in the other three conditions $(M=4.24), t(154)=2.41, p<.01$. More specifically, covering the perpetrators was considered as less illegitimate when perpetrator group was egalitarian rather than hierarchical when the victim group was hierarchical, $t(154)=2.61, p<.01$, but not when victims were egalitarian, $t(154)=0.24, p<.80$. Finally, covering perpetrators tended to appear as less illegitimate when victims were egalitarian rather than hierarchical, when the perpetrator group was egalitarian, $t(154)=1.75, p<.09$, but not when perpetrators were hierarchical, $t(154)=1.57$, $p<.12$. Overall, these results parallel those found for the individual-level aggression.

\section{IDENTIFICATION WITH PERPETRATOR AND VICTIM GROUPS}

The $2 \times 2 \times 2 \times 2$ mixed ANOVA performed with identification scores as repeated measures and the experimental factors as between-subjects factors showed a main effect of the within-subjects factor, $F(1,149)=18.65, p<$ .001 , indicating that participants identified more with the victims than with the perpetrators. This effect was again moderated by the interaction between the withinsubjects factor and the victim group structure, $F(1,149)=$ $15.79, p<.001$, and by the interaction between the within-subjects factor and the perpetrator group structure, $F(1,149)=27.50, p<.001$.

In regard to within-subjects comparisons, greater identification with the victims $(M=3.00)$, as compared to the perpetrators $(M=2.30)$, was observed when the victim group was egalitarian, $p<.001$, but not when victims were hierarchical (respectively, $M s=2.36$ and 2.32), $p<.80$. Identification with the victims $(M=2.75)$ was also higher than with the perpetrators $(M=1.90)$ when the perpetrator group was hierarchical, $p<.001$, but not when this group was egalitarian (respectively, $M s=2.79$ and 2.70$), p<.40$. In regard to between-subjects comparisons, analyses showed that identification with the perpetrator group, although very low in general, was higher when this group was egalitarian than when it was hierarchical, $p<.001$. Similarly, identification with the victim group was greater when it was egalitarian rather than hierarchical, $p<.001$. No other effect was significant. In sum, participants again identified more strongly with victims than with perpetrators but identification with the victim group was highest when this group was egalitarian and lowest with perpetrators when this group was hierarchical.

To examine whether the identification scores mediated the effect of group structure on illegitimacy perceptions, we followed again the procedure suggested by Baron and Kenny (1986) separately for each identification score. ${ }^{4}$ First, the contrast relative to the interaction hypothesis $(1,-3,1,1)$ was significantly related to the perceived illegitimacy of the aggression, $\beta=-.24, p<.002$ (see previous analyses). Second, identification with the perpetrator group was significantly related to perceived illegitimacy, $\beta=-.22, p<.005$, while identification with the victim group was not, $\beta=-.12, p<.11$. Third, the experimental contrast was related to the identification with the perpetrator group, $\beta=.25, p<.001$, but not to the identification with the victim group, $\beta=-.09, p<.25$. Therefore, identification with the victim group cannot be considered as a mediator. Finally, when perceived illegitimacy was regressed onto both the experimental contrast and identification with the victim group, the analysis showed that both factors slightly reduced their contribution, but they remained significant: experimental contrast, $\beta=-.18, p<.03, Z_{\text {Sobel }}=1.82, p<.07$, and identification with the perpetrator group, $\beta=-.17, p<.04$. In sum, the effect of group structure on the perceived illegitimacy of the aggression seems to be partially mediated by the identification with the members of the perpetrator group, but the reduction is only marginal. 


\section{Discussion}

The results of the mixed ANOVA showed that the perceived legitimacy of both the individual and the grouplevel aggressions followed the same pattern. Furthermore, these results replicated those obtained in Experiment 1 in regard to the interaction between the perpetrator and victim group structure but also revealed a significant main effect of the perpetrator group structure and a main effect of the severity of the aggression.

Individual aggression was considered the least illegitimate when perpetrated by members of an egalitarian group against hierarchical victims. As in Experiment 1, planned comparisons confirmed that the condition in which the perpetrator group was egalitarian and the victim group was hierarchical significantly differed from the pooled other conditions. The fact that the interaction was only marginally significant (whereas it was significant in Experiment 1) can be explained by the fact that the experimental design included an additional factor and that two main effects also were significant. These two main effects are interesting in their own right. On one hand, a more severe aggression was evaluated as more illegitimate than a less severe one. This is consistent with a well-known effect: the severity of the aggression's consequences is a major factor in the evaluation of the legitimacy of aggressive behavior (Robbennolt, 2000). However, this factor did not interact with the group structure factors, suggesting that the observed effect of group structure did not depend on the level of severity of the aggression. On the other hand, the main effect of the perpetrator group structure showed that an aggressive act committed by an egalitarian group was judged as less illegitimate than the same act committed by a hierarchical group. That this effect did not appear for the victim group structure could be explained by the greater salience of the perpetrator group in the context of our intergroup aggression. In sum, these findings suggest that the legitimacy of aggressive acts may be evaluated by merely considering the political structure of the perpetrator group.

Of importance, this experiment showed the predicted pattern not only for an individual-level aggression but also for a group-based behavior, namely, the covering of perpetrators by their fellow group members. Members of the perpetrator group were said to have been aware of the perpetrators' identities and to have covered them. Most participants viewed this as a reprehensible act, as demonstrated by a relatively high level of perceived illegitimacy. Our results showed that this recognition was moderated by the internal structure of the groups: Covering was somewhat condoned when the perpetrator group was egalitarian and the victim group was hierarchical. Furthermore, the two main effects of aggression severity and perpetrator group structure were significant. Both effects matched those observed for the legitimacy of the aggressive act committed by individual group members. Because both individual and group-level actions yielded the same patterns of perceived legitimacy, this finding supports the interpretation that legitimacy judgments reflect the higher social worth of egalitarian groups rather than a motivation to minimize the gravity of an individual act inconsistent with the positive image associated to egalitarian groups.

Participants again identified more strongly with victim than with perpetrator groups and more with egalitarian than with hierarchical groups. However, in this experiment, this last effect was true for both the perpetrator and the victim groups. The results of the mediation analyses suggest that the effect of the political structure of the groups on the perceived illegitimacy of the aggression may be partially explained by a greater identification with the egalitarian perpetrator group when the victims belong to a hierarchical group. However, because the effect of the experimental factor remained significant once the identification scores were included into the equation, the reduction in explained variance was only marginal, and this reduction appeared only in Experiment 2, it may be argued that the effect of the political structure cannot merely be reduced to a greater identification with egalitarian groups.

\section{GENERAL DISCUSSION}

The present research was carried out to demonstrate that the perceived legitimacy of intergroup aggression is moderated by the political structure of rival groups. In two studies, we observed a high baseline level of perceived illegitimacy of the aggression depicted in our scenario. Yet, findings from both studies supported the hypothesis that aggressions are evaluated as less illegitimate when the perpetrator group is egalitarian and the victim group is hierarchical. Despite the fact that the interaction effect was only marginally significant in Experiment 2, the predicted pattern of perceived legitimacy was observed across both studies, and with different types of behaviors, thereby providing repeated and convergent support for this hypothesis.

Overall, these findings suggest that attributes (namely, political decision-making procedures) are used as inference cues for judgments of particular group members and their behaviors (Allison \& Messick, 1987). We assumed that rather than dissociating the system and its members when judging structured groups, perceivers represent group members as a function of egalitarian or hierarchical decision-making procedures. But the 
inferences drawn from democratic and authoritarian decision-making procedures are not value neutral. At least in Western societies, egalitarian-democratic groups are perceived as more valued than hierarchical and nondemocratic groups because psychological attributes necessary for egalitarian group structures (e.g., independence and individual autonomy) are culturally more valued than hierarchy-reflecting attributes such as obedience and compliance (Beauvois, 2005; Lorenzi-Cioldi, 1998). In addition, we suggested that social value attribution to groups also was derived from democratic procedures themselves, which are perceived as intrinsically more legitimate than hierarchical procedures (Lind \& Tyler, 1988) because all group members can voice and have equal power.

The results on perceived legitimacy are in line with this explanatory framework. Our cover story stressed that the aggression was initiated by isolated group members and not by collective decisions. Moreover, findings of the second experiment indicated that the political structure of the groups determines both the perceived legitimacy of a group-level misdeed (covering ingroup perpetrators) and individual aggressions (isolated attacks on outgroup members) that are not the result of a collective deliberation. In other terms, both collectively and individually decided actions performed by isolated members of an egalitarian group at the expense of a hierarchical group may be granted relative legitimacy. It should nevertheless be noted that the present research did not systematically control for individual and grouplevel aggressions. Future research is therefore needed to examine more specifically to what extent the political structure of the groups determines perceived legitimacy of intergroup aggression with and without collective decision making.

In both studies, identification appeared to be higher with the victim than with the perpetrator group and with the egalitarian than with the hierarchical groups. In both experiments, identification with the perpetrator group was related to perceived legitimacy of aggression, and in Experiment 2, perpetrator identification tended to partially mediate the effect of group structure on perceived illegitimacy. However, this effect should be considered with caution because it was not observed in Experiment 1 and because the Sobel test did not reach the conventional significance level. It is clear, therefore, that even though identification with groups may to some extent reflect the greater social value attributed to egalitarian groups, the effect of the political structure of the groups on the perceived legitimacy of the aggression cannot be reduced to greater identification with egalitarian groups. Indeed, both experiments showed that the political structure of the groups predicted illegiti- macy judgments independently from the level of identification with the groups. Furthermore, identification scores did not predict perceived illegitimacy of covering perpetrators. True, these effects may be due to the low identification scores observed in this paradigm, but it also should be reminded that we derived our hypothesis from the greater value associated to the egalitariandemocratic groups and from the lower value associated to hierarchical-nondemocratic groups. Therefore, group identification is not a sufficient indicator of such a value attributed to egalitarian-democratic groups. To specify this contribution, future research will have to study how social value attributed to these groups (e.g., in terms of normatively valued cultural and ideological attributes) underlies the observed effect on the perceived illegitimacy of intergroup aggression.

Finally, we should pinpoint several other limitations of the present experiments. First, participants were mostly young female university students from a Western European country. It would be worthwhile to generalize the observed findings to participants from different backgrounds because they might not endorse the same stereotypes of egalitarian and hierarchical groups. Future research is needed to overcome these limitations related to the sampling of participants. Second, our experimental manipulation was somewhat abstract and artificial and therefore quite far removed from the realworld processes we were trying to mimic. It remains to be seen whether the observed dynamics are reproduced when considering real groups as well as when participants clearly perceive perpetrators and victims as belonging to ingroups and outgroups. This seems particularly important for more thorough analyses of the role of identification and categorization processes in the construction of legitimacy judgments.

To conclude, we should acknowledge that this research grew out of concrete concerns about international politics at the beginning of this millennium. The results of the present studies provide potentially important insights for understanding how real intergroup and international conflicts are framed by elites to maximize their legitimacy and attract the necessary popular support (Nelson \& Kinder, 1996). Many past and recent military interventions have been justified by portraying them as an opposition between "good," democratic forces and "evil," nondemocratic forces. Unfortunately, such a claim has a high price because it implies that democratic lives count more than nondemocratic lives. We hope that the present research can contribute to a better understanding of the dynamics underlying not only public support for but also widespread opposition to Western-democratic aggressions against nondemocratic targets. 


\section{NOTES}

1. All the analyses have been rerun without male participants. Although less powerful, the results remained the same.

2. Although the effectiveness of our manipulations was confirmed, the unexpected effects on the perception of the perpetrator and the victim group deserve some consideration. They suggest that in our experimental context, group perception is relative rather than absolute, that is, by comparison, the induced structure of one group influenced the perception of the other group. More specifically, they can be understood in light of the beforehand stressed egalitarian-hierarchical asymmetry: An implicit association between egalitarian groups and peaceful solutions of conflict, on one hand, and hierarchical groups and aggressive solutions, on the other. Indeed, the perpetrator group was perceived as more hierarchical not only when the cover story clearly stated so but also when the aggression was more violent and when the victims were described as egalitarian (because egalitarian groups are expected to embrace negotiation and support peaceful solutions, they should be aggressed only by hierarchical groups). Similarly, the victim group was perceived as more hierarchical not only when the cover story clearly stated so but also when the perpetrator group was egalitarian (egalitarian perpetrators are less likely to aggress but the hierarchical nature of the victim group prevented a peaceful solution). The interaction effect is to a great extent understandable in the same terms. Notwithstanding the relevance of these effects, additional correlation and covariation analyses showed that these group perceptions did not affect the perceived legitimacy of the aggression and, therefore, have no impact on our understanding of the main findings.

3. Again, all the analyses have been rerun without male participants. The results remained the same and significant.

4. The mediation effect was not examined for the perceived illegitimacy of covering because this perception was not correlated with any of the identification scores (perpetrator group, $r=-.09$, and victim group, $r=-.01$ ).

\section{REFERENCES}

Allison, S. T., \& Messick, D. M. (1987). From individual inputs to group outputs, and back again: Group processes and inferences about members. In C. Hendrick (Ed.), Review of personality and social psychology (Vol. 8, pp. 111-143). Thousand Oaks, CA: Sage.

Azzi, A. E., \& Jost, J. T. (1997). Votes without power: Procedural justice as mutual control in majority-minority relations. Journal of Applied Social Psychology, 27, 124-155.

Baldus, D. C., Woodworth, G., \& Pulanski, C. A., Jr. (1990). Equal justice and the death penalty: A legal and empirical analysis. Boston: Northeastern University Press.

Baron, R. M., \& Kenny, D. A. (1986). The moderator-mediator variable distinction in social psychological research: Conceptual, strategic, and statistical considerations. Journal of Personality and Social Psychology, 51, 1173-1182.

Beauvois, J. L. (2005). Les illusions libérales, individualisme et pouvoir social: Petit traité sur des grandes illusions [Liberal illusions, individualism and social power: Little treatise on big illusions]. Grenoble, France: Presses Universitaires de Grenoble.

Berkowitz, L. (1993). Aggression: Its causes, consequences, and control. New York: McGraw-Hill.

Bushman, B. J., \& Anderson, C. A. (2001). Is it time to pull the plug on the hostile versus instrumental aggression dichotomy? Psychological Review, 108, 273-279.

Crandall, C. S., \& Beasley, R. K. (2001). A perceptual theory of legitimacy: Politics, prejudice, social institutions, and moral value. In J. T. Jost \& B. Major (Eds.), The psychology of legitimacy: Emerging perspectives on ideology, justice, and intergroup relations (pp. 77-102). New York: Cambridge University Press.

Doyle, M. (1983). Kant, liberal legacies, and foreign affairs. Philosophy and Public Affairs, 12, 205-235.

Dumont, M., Yzerbyt, V., Wigboldus, D., \& Gordijn, E. H. (2003). Social categorization and fear reactions to the September 11th terrorist attacks. Personality and Social Psychology Bulletin, 29, 15091520.

Feather, N. (1999). Judgments of deservingness: Studies in the psychology of justice and deservingness. Personality and Social Psychology Review, 3, 86-107.

Fincham, F. D., \& Jaspars, J. M. (1980). Attribution of responsibility: From man the scientist to man the lawyer. Advances in Experimental Social Psychology, 13, 81-138.

Gordijn, E. H., Wigboldus, S., \& Yzerbyt, V. (2001). Emotional consequences of categorizing victims of negative outgroup behavior as ingroup or outgroup. Group Processes E Intergroup Relations, 4, 317326.

Hart, H. L. A. (1968). Punishment and responsibility. New York: Oxford University.

Healy, A. F., Hoffman, J. M., Beer, F. A., \& Bourne, L. E., Jr. (2002). Terrorist and democrats: individual reactions to international attacks. Political Psychology, 23, 439-467.

Jones, E. E., \& Davis, K. E. (1965). From acts to dispositions: The attribution process in person perception. Advances in Experimental Social Psychology, 2, 219-266.

Kelley, H. H. (1973). The process of causal attribution. American Psychologist, 28, 107-128.

Lerner, M. J. (1980). The belief in a just world: A fundamental delusion. New York: Plenum.

Lind, E. A., \& Tyler, T. R. (1988). The social psychology of procedural justice. New York: Plenum.

Lorenzi-Cioldi, F. (1998). Group status and perceptions of homogeneity. In W. Stroebe \& M. Hewstone (Eds.), European review of social psychology (Vol. 9, pp. 31-75). Chichester, UK: Wiley.

Malle, B. F. (1999). How people explain behavior: A new theoretical framework. Personality and Social Psychology Review, 3, 23-48.

McKillip, J., \& Posavac, E. J. (1975). Judgments of responsibility for an accident. Journal of Personality, 43, 248-265.

Milgram, S. (1974). Obedience to authority: An experimental view. New York: Harper \& Row.

Miller, D. T. (2001). Disrespect and the experience of injustice. Annual Review of Psychology, 52, 527-553.

Nelson, T. E., \& Kinder, D. R. (1996). Issue frames and group-centrism in American public opinion. Journal of Politics, 58, 1055-1078.

Reeder, G. D., \& Brewer, M. B. (1979). A schematic model of dispositional attribution in interpersonal perception. Psychological Review, 86, 61-79.

Reeder, G. D., Kumar, S., Hesson-McInnis, M. S., \& Trafimow, D. (2002). Inferences about the morality of an aggressor: The role of the perceived motive. Journal of Personality and Social Psychology, 83, 789-803.

Robbennolt, J. K. (2000). Outcome severity and judgments of "responsibility": A meta-analytic review. Journal of Applied Social Psychology, 3, 2575-2609.

Sampson, E. E. (1988). The debate on individualism: Indigenous psychologies of the individual and their role in personal and societal functioning. American Psychologist, 43, 15-22.

Shaver, K. G. (1970). Defensive attribution: Effects of severity and relevance on the responsibility assigned for an accident. Journal of Personality and Social Psychology, 14, 101-113.

Staerklé, C. (2005). L'idéal démocratique perverti: Antagonismes dans les représentations du non-occident [The perverted ideal of democracy: Antagonism in representations of the non-West]. In M. Sanchez-Mazas \& L. Licata (Eds.), L'autre: Regards psychosociaux [The other: Psychosocial views] (pp. 117-148). Grenoble, France: Presses Universitaires de Grenoble.

Staerklé, C., Clémence, A., \& Doise, W. (1998). Representation of human rights across different national contexts: The role of democratic and non-democratic populations and governments. European Journal of Social Psychology, 28, 207-226.

Staub, E. (1989). The roots of evil: The origins of genocide and other group violence. New York: Cambridge University Press.

Tajfel, H., \& Turner, J. C. (1986). The social identity theory of intergroup behaviour. In S. Worchel \& W. G. Austin (Eds.), Psychology of intergroup relations (pp. 7-24). Chicago: Nelson-Hall. 
Tyler, T. R. (1997). The psychology of legitimacy: A relational perspective on voluntary deference to authorities. Personality and Social Psychology Review, 1, 323-345.

Yzerbyt, V., \& Rogier, A. (2001). Blame it on the group: Entitativity, subjective essentialism, and social attribution. In J. T. Jost \& B. Major (Eds.), The psychology of legitimacy: Emerging perspectives on ide- ology, justice, and intergroup relations (pp. 103-134). New York: Cambridge University Press.

Received April 10, 2004

Revision accepted April 5, 2005 